\title{
The Bayesian Inferential Paradigm in Archaeology
}

\author{
ERIK OTÁROLA-CASTILLO*, MELISSA G. TORQUATO \\ Department of Anthropology, Purdue University, West Lafayette, Indiana, USA \\ CAITLIN E. BUCK* \\ School of Mathematics and Statistics, University of Sheffield, Sheffield, UK \\ R Markdown version last compiled on Wednesday November 17 2021, 11:2\%:10 AM, EST
}

Manuscript accepted to the Handbook of Archaeological Sciences, 2nd ed. Forthcoming volume under contract (2022). Edited by M. Pollard, R.A. Armitage, and C.M. Makarewicz. Wiley.

*Corresponding Authors

email: eoc@purdue.edu

email: c.e.buck@sheffield.ac.uk 


\section{INTRODUCTION}

Archaeologists often use data and quantitative statistical methods to evaluate their ideas. Although there are various statistical frameworks for decision-making in archaeology and science in general, in this chapter, we provide a simple explanation of Bayesian statistics. To contextualize the Bayesian statistical framework, we briefly compare it to the more widespread null hypothesis significance testing (NHST) approach. We also provide a simple example to illustrate how archaeologists use data and the Bayesian framework to compare hypotheses and evaluate their uncertainty. We then review how archaeologists have applied Bayesian statistics to solve research problems related to radiocarbon dating and chronology, lithic, ceramic, zooarchaeological, bioarchaeological, and spatial analyses. Because recent work has reviewed Bayesian applications in archaeology from the 1990s up to 2017 (Caitlin E. Buck, Cavanagh, and Litton 1996; Caitlin E. Buck 2001; Otárola-Castillo and Torquato 2018), this work considers the relevant literature published since 2017.

\section{Null hypothesis significance testing}

Archaeologists use NHST to assess the extent to which well-observed material culture recovered from archaeological sites aligns with their hypotheses about past people. Statisticians pioneered the NHST inferential structure in the early twentieth century and, thanks to its success in research practice, it became widely available to scientists of the time (e.g., R. A. Fisher 1925; Neyman and Pearson 1933: 294). In the 1950s, various science-oriented archaeological works introduced NHST methodology to the field (e.g., Myers 1950; Spaulding 1953; Binford 1964; Clarke 1968). Today, numerous textbooks continue to teach archaeological scientists introductory NHST statistical concepts such as confidence intervals and p-values (e.g., Fletcher and Lock 2005; Carlson 2017; McCall 2018; Banning 2020).

Statistical methods that follow the NHST framework provide inference by estimating the parameters of a probability model used to represent the salient features of a population (e.g., the mean and variance). Scientists usually hypothesize the value of the population's parameters - the so-called "null" hypothesis - and design experiments or observational studies to generate quantifiable data that can be used to test it. After observation, the data are compared to the null hypothesis' assumptions using a probability measure known as the p-value. This comparative procedure first assumes a probability model for the underlying population, then evaluates whether the data collected are expected or probable outcomes of that population, and thus whether the null hypothesis is (plausibly) true.

A large p-value, usually greater than 0.05 , indicates that the data are not extreme and "fails to reject" the null hypothesis. By contrast, a small or "significant" p-value, usually less than 0.05 , indicates that the data are extreme and have a low probability with respect to the assumptions stated in the null hypothesis. 
In this case, investigators may "reject the null hypothesis" in favour of an alternative hypothesis. In short, to arbitrate between hypotheses, NHST uses the probability that the stated null hypothesis generated the data.

Although this approach is one of the most widely used inferential frameworks across the sciences, it has had its share of criticism (e.g., Gelman 2006, 2018; Vidgen and Yasseri 2016). For example, statisticians have recently targeted p-values mainly for their arbitrariness and misuse (Wasserstein, Schirm, and Lazar 2019). Although some mistake statistical significance for practical significance (e.g., Kramer, Veile, and Otárola-Castillo 2016), the interpretation of significant p-values, in terms of rejecting the null hypothesis, is well understood. However, how to interpret non-significant p-values is less clear. Similarly, the NHST toolkit does not include acceptance of a null hypothesis. Nevertheless, some misunderstand this point and attempt to use NHST to verify their null hypotheses.

Language appears to be part of the problem here, but failing to reject a null hypothesis is not synonymous with accepting it. Instead, "failing to reject" means that there is not enough evidence to invalidate the null hypothesis. Moreover, the relationship between probabilities and alternative hypotheses is not clear and is often misunderstood (Benjamin and Berger 2019). In particular, it is challenging to evaluate multiple alternative hypotheses within the NHST framework. Indeed, the ability to assign probabilities to multiple hypotheses in light of the data is one of the many reasons researchers have turned to Bayesian statistics.

\section{BAYESIAN STATISTICS}

During the late twentieth century, scientists popularized Bayesian inference, a statistical approach based on developments made in the eighteenth century by Reverend Thomas Bayes (1763). Bayes was an English Presbyterian minister and mathematician who solved problems in probability involving conditional and prior probabilities (Bellhouse 2004). Soon after the popularization of Bayesian inference in the sciences, archaeologists also incorporated Bayesian methods into their toolkits to evaluate hypotheses (e.g., Caitlin E. Buck, Cavanagh, and Litton 1996). Today, Bayesian methods have proliferated throughout the scientific literature, including in anthropological and archaeological science (Gelman et al. 2020; Otárola-Castillo and Torquato 2018; McElreath 2020). In the past, feasible execution of Bayesian methods was difficult because some calculations are intractable and require intensive computation. Today's powerful personal computers and high-speed Markov Chain Monte Carlo (MCMC) algorithms, such as the Metropolis-Hastings, Gibbs, and Hamiltonian procedures, have helped to overcome this obstacle and further popularize the approach (e.g., Howson and Urbach 2006 :xi; Robert and Casella 2011; Dunson and Johndrow 2020).

Another reason for Bayesian approaches' increased popularity might be the simplicity of interpreting probabilities compared to the p-values used in NHST (Otárola-Castillo and Torquato 2018). Scientists apply 
Bayesian inference to compute the probability of a hypothesis directly and thus obtain clearer and more direct interpretations than those available from NHST. Also, as with NHST, the degree to which the given hypothesis supports the data is computed, usually via an explicit probability model, known as a likelihood. We formally define these terms below, but in summary, the likelihood is a statistical function whose form is determined by the specific probability model we are using. Crucially, Bayesian inference enables researchers to incorporate their expert (or prior) knowledge about the hypothesis into the statistical analysis. Experts' prior knowledge in a field can be quite valuable; however, it is not often operationalized. Practitioners of Bayesian inference convert prior knowledge into prior probabilities and use them as part of statistical analyses. Once the prior probability has been determined, as with NHST, new data are observed to test the hypothesis. The likelihood is combined with (or weighted by) the prior to give the Bayesian posterior distribution. From this, the probability of the hypothesis given the observed data and the prior knowledge can be computed (Caitlin E. Buck, Cavanagh, and Litton 1996). These steps, including the formalization of a simple prior probability, likelihood, and computation of the posterior will be exemplified below in a simple archaeological example.

The primary advantage of Bayesian statistics over NHST is the clarity of the inferences drawn from the analysis. Furthermore, by formally including previous experience or expert information, prior probabilities offer practical improvements over NHST, typically reducing uncertainty in the conclusions reached (George L. Cowgill 2001). Including prior knowledge produces a comprehensive understanding of the proposed hypothesis' relevance to a larger body of knowledge. Moreover, incorporating prior probabilities enables Bayesian inferences to be "updated," creating a cyclical effect as current knowledge becomes prior knowledge for future studies. Perhaps Dennis Lindley (1972) best summarized the Bayesian learning process by writing the aphorism "today's posterior is tomorrow's prior." Helpfully, it is also possible to use what is known as a flat, vague, or uninformative prior (as we do in our example below) in situations where little or no expert prior knowledge is available, but one may wish to take advantage of the other features of the Bayesian framework.

To further contextualize the application of Bayesian statistics, we provide an example that illustrates how one can use Bayesian statistics to select a hypothesis and solve an archaeological research problem. The example demonstrates how archaeologists can make probabilistic inferences using data and simple prior information about a hypothesis, how to evaluate the uncertainty surrounding a hypothesis, why this approach seems less ambiguous than NHST, and thus why it is becoming increasingly popular. We also formally define the Bayesian framework and review recent Bayesian statistics applications in the archaeological literature. 


\section{A SIMPLE ARCHAEOLOGICAL EXAMPLE}

Otárola-Castillo and Torquato (2018) introduced a simple example to contrast NHST and Bayesian inference. They presented an artificial case study where an archaeologist proposed to infer projectile propelling technology from its relationship to stone projectile morphology. In their example, the archaeologist used the known relationship between projectile point propelling technology and point size, from an ethnographic context. The archaeologist used this relationship as a frame of reference to infer the propelling technology of a sample of stone projectile points recovered from a multi-component archaeological site. Using known measurements of each technology type, Otárola-Castillo and Torquato (2018) demonstrated how the archaeologist could use NHST and a Bayesian framework to infer the most likely propelling technology (Table $1)$.

Table 1 Summary statistics (mean and standard deviation) of artificial maximum projectile point lengths recovered from the Early and Late Period archaeological contexts, along with equivalent summaries of the maximum point lengths known to be associated with different propelling technologies. The latter are used to define the hypotheses to be evaluated using the archaeological data.

\section{Archaeological Projectile Data}

\begin{tabular}{lll}
\hline & Early Period & Late Period \\
\hline Mean Length $(\mathrm{cm})$ & 6.1 & 13 \\
$\mathrm{SD}(\mathrm{cm})$ & 2 & 3.2 \\
$\mathrm{~N}$ & 10 & 9 \\
\hline
\end{tabular}

\section{Propelling Hypotheses}

\begin{tabular}{lccc}
\hline & Arrow & Dart & Spear \\
\hline Mean Length $(\mathrm{cm})$ & 6.9 & 11 & 14 \\
$\mathrm{SD}(\mathrm{cm})$ & 2 & 2 & 2 \\
\hline
\end{tabular}

The simulated data are maximum length measurements of projectile points from the Early $(\mathrm{N}=10)$ and Late (N=9) components of an archaeological site (upper part of Table 1). The archaeologist also measured the maximum lengths of a large sample of ethnographic projectile points with known propelling technology, summarized in the lower part of Table 1 by their means and standard deviations. The hypotheses to be tested 
are that the archaeological data from the Late and Early Period derive from each of the three ethnographically observed propelling technologies: 1) bow and arrow, 2) atlatl and dart, and 3) hand-thrown spear.

\section{Analysis using NHST}

The archaeologist tested the hypotheses that the archaeological data were plausible given the ethnographic data relating to each propelling technology. To do this, they used the means () in Table 1 and formalized the hypotheses shown in Table 2.

Table 2 Null and alternative hypotheses used for NHST.

\section{$\mathrm{H}_{0^{-}}$the null hypotheses}

\begin{tabular}{ll}
\hline Early Period & Late Period \\
\hline$\mu_{\text {Early Period }}=\mu_{\text {Arrow }}$ & $\mu_{\text {Late Period }}=\mu_{\text {Arrow }}$ \\
$\mu_{\text {Early Period }}=\mu_{\text {Dart }}$ & $\mu_{\text {Late Period }}=\mu_{\text {Dart }}$ \\
$\mu_{\text {Early Period }}=\mu_{\text {Spear }}$ & $\mu_{\text {Late Period }}=\mu_{\text {Spear }}$ \\
\hline
\end{tabular}

\section{$\mathrm{H}_{\mathrm{A}^{-}}$the alternative hypotheses}

\begin{tabular}{ll}
\hline Early Period & Late Period \\
\hline$\mu_{\text {Early Period }} \neq \mu_{\text {Arrow }}$ & $\mu_{\text {Late Period }} \neq \mu_{\text {Arrow }}$ \\
$\mu_{\text {Early Period }} \neq \mu_{\text {Dart }}$ & $\mu_{\text {Late Period }} \neq \mu_{\text {Dart }}$ \\
$\mu_{\text {Early Period }} \neq \mu_{\text {Spear }}$ & $\mu_{\text {Late Period }} \neq \mu_{\text {Spear }}$ \\
\hline
\end{tabular}

They then assumed that the summaries in Table 1 were for samples from populations distributed under "Normal" probability models and applied the well-known z-test (Diez, Barr, and Cetinkaya-Rundel 2019: 134). The same Normal probability model assumptions will also be useful to generate the likelihood function in the Bayesian analysis, later on. Knowing the means and standard deviations of the ethnographic and archaeological data, Otárola-Castillo and Torquato (2018)'s archaeologist computed the z-scores and their associated p-values (Table 3). 
Table 3 Results of the $z$-score hypothesis tests described in the text, including the associated p-values.

\section{Early Period}

\begin{tabular}{lll}
\hline & z-score & p-value \\
\hline Arrow & -1.26 & 0.21 \\
Dart Tips & -7.75 & $<0.001$ \\
Spear Tips & -12.49 & $<0.001$ \\
\hline
\end{tabular}

\section{Late Period}

\begin{tabular}{lll}
\hline & z-score & p-value \\
\hline Arrow & 5.71 & $<0.001$ \\
Dart Tips & 1.87 & 0.06 \\
Spear Tips & 0.94 & 0.35 \\
\hline
\end{tabular}

Using this method, because the p-values were less than 0.001, they rejected the null hypotheses that the means of the Early Period projectile points resembled those of darts or spears (Tables 2 and 3). Instead, the archaeologist determined that the points may have come from a population of arrow projectile points because the associated p-value is greater than 0.05 (Table 3). Thus, there was not enough evidence to reject this null hypothesis. NHST allows the archaeologist to infer that "the Early Period sample does not have a low probability of resulting from a population of arrow tips," and they do not reject this hypothesis.

Following this exact procedure for the Late Period, the archaeologist obtained a p-value less than 0.001 for the arrow hypothesis. However, the p-values for the speartip and dart tip hypotheses are both greater than 0.05. Therefore, although the archaeologist may reject the arrow hypothesis, the inference cannot be distinguished between "the sample does not have a low probability of resulting from a population of dart tips" and "the sample does not have a low probability of resulting from a population of spear tips".

\section{Bayesian analysis}

Otárola-Castillo and Torquato (2018)'s archaeologist then compared the NHST analysis to one using a Bayesian framework. The authors did this to show how archaeologists might apply Bayesian statistics to assign probabilities to the hypotheses that the archaeological projectile points were arrows, dart tips, or spear tips - given the data in hand. 


\section{Early Period}

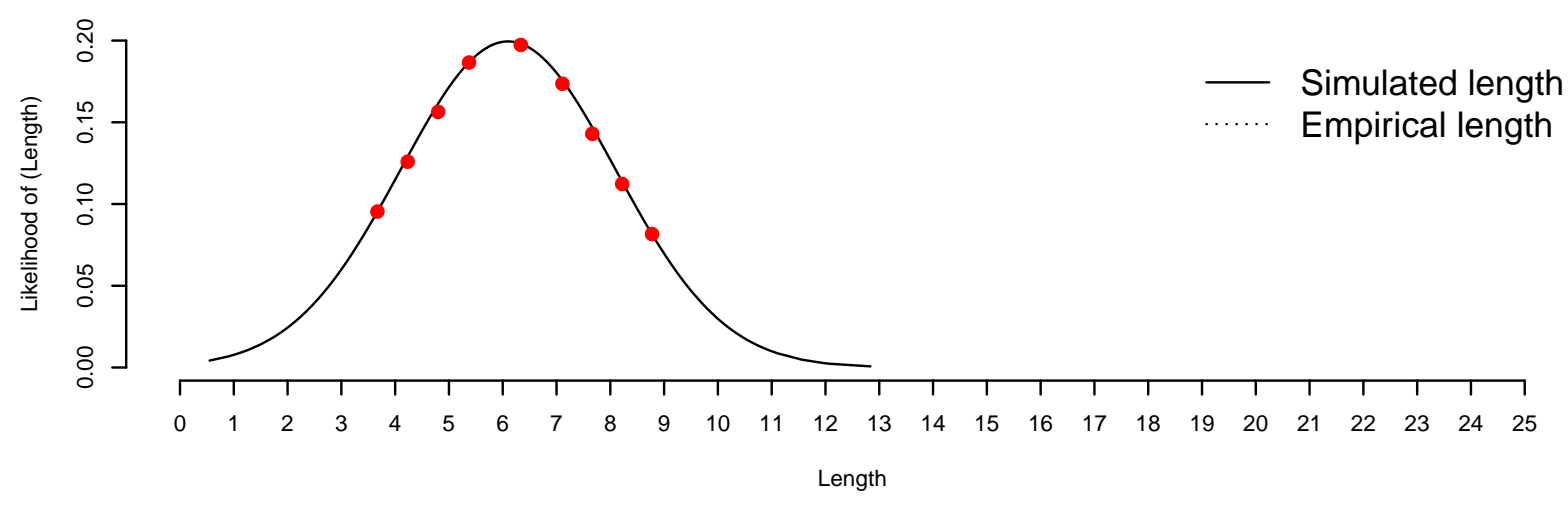

Late Period

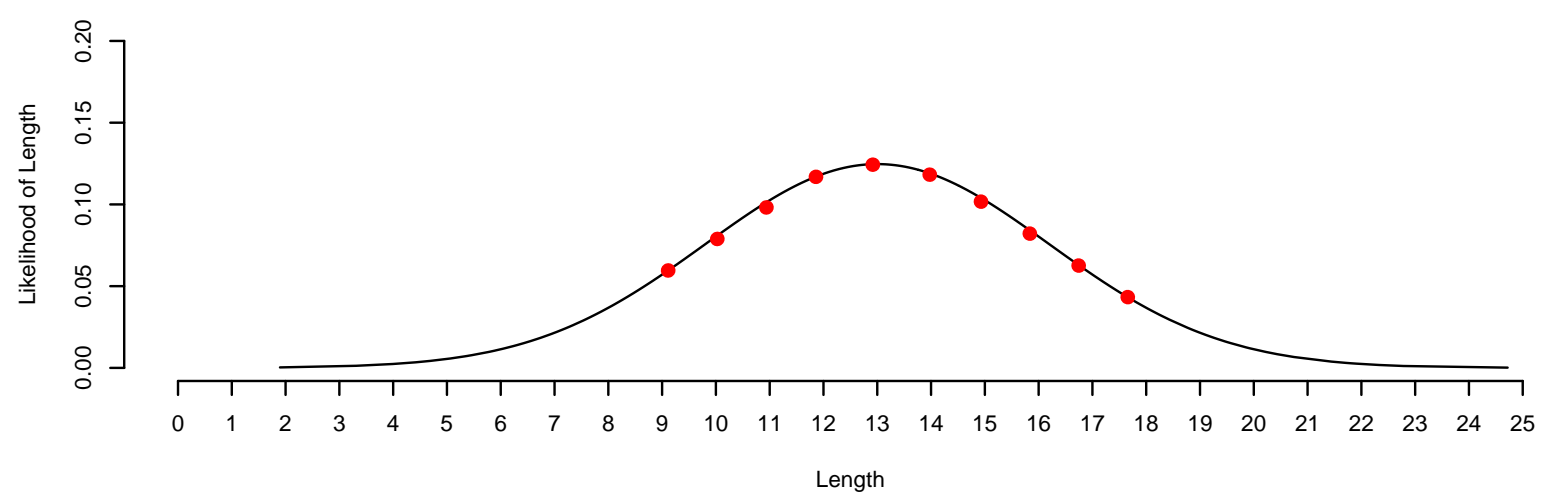

Figure 1: Figure 1 Likelihoods of the maximum length data. The red dashed lines illustrate the "Normal" likelihood of the maximum lengths data measurements obtained empirically from the archaeological Early (top) and Late (bottom) periods. The likelihood values were obtained after estimating the parameters of the Normal probability distribution that maximized the likelihood of the measurement values (i.e., Maximum Likelihood Estimation, MLE). Following this procedure, we used the MLE parameter estimates to simulate the likelihood of hypothetical maximum length values greater than the range observed archaeologically. The black solid line depicts these values. In both panels, we overlaid the empirical (gray dotted) over the hypothetical (black solid) likelihood estimates for comparison 
This approach is advantageous when a scientist uses multiple working hypotheses and is interested in deciding which is most probably supported by the data. The Bayesian framework can achieve this goal by using the same assumptions about the underlying probability distributions as those in the NHST approach. Using Bayes' theorem, one may then represent prior knowledge as a corresponding prior probability distribution and calculate each hypothesis's posterior probability.

To conduct this analysis, Otárola-Castillo and Torquato followed the procedures on likelihoods, prior and posterior probabilities, and MCMC sampling we outlined in our Bayesian Statistics section above. For additional technical detail, we refer the reader to the What is Bayes' Theorem section below. The authors modelled the likelihood of the maximum projectile length using the "Normal" probability model (Figure 1). They also modelled prior knowledge using a uniform probability distribution to reflect no previous information and demonstrate the probabilistic approach to hypothesis selection. Under the uniform distribution, the prior probabilities of all maximum projectile lengths were identical. Together, the likelihood and prior probability models are foundational components of Bayesian Inference.

The archaeologist in Otárola-Castillo and Torquato (2018) then used an MCMC procedure to calculate the probability of each hypothesis: that the archaeological samples were either arrow, dart, or spear, applying a two-step process. First, they generated samples from the posterior distribution via MCMC. Second, they compared the sampled values to intervals defined by one standard deviation around the mean of the ethnographically observed values for each of the point types (Table 4, Figure 2). In this way, sampled posterior point lengths that lay between $4.9 \mathrm{~cm}$ and $8.9 \mathrm{~cm}$ were defined (a posteriori) as Arrows; those in the range 9 to $13 \mathrm{~cm}$ Darts; those in 12 to $16 \mathrm{~cm}$ Spears. Point lengths outside the range of 4.6 to 16 $\mathrm{cm}$ were outside of the evaluated hypotheses. Therefore, they were declared to belong to a group labelled "Other." There is some overlap between the summary probability distributions implied by the ethnographic data. Thus, the hypotheses are not mutually exclusive. In other words, due to overlapping measurements, some projectile points may be consistent with more than one hypothesis. We discuss the implications of this overlap below.

Next, the archaeologist calculated the posterior probabilities by dividing the number of projectile points consistent with each hypothesis by the total number of projectile points for each period. The posterior probability of point lengths for each hypothesis is reported in Table 4 and illustrated in Figure 2. Since the hypotheses are non-mutually exclusive, the posterior probabilities corresponding to each hypothesis within a period are not expected to sum to 1. Depending on one's hypotheses, the interpretation of probabilities relating to non-mutually exclusive outcomes may be problematic. For example, one might ask, what is the probability that the projectile points are Arrows or Darts? In this case, because some Arrows may be similar in length to Darts, these are not mutually exclusive outcomes, and one may not simply add their respective 
probabilities together. The solution is to use the General Addition Rule of probability (see Diez, Barr, and Cetinkaya-Rundel (2019): 83-88). We do not evaluate such an hypothesis in this example but note this rule so that readers may adopt it if needed for their own work.

Using the resulting Bayesian posterior probability distribution to conduct inference lets scientists make fully probabilistic statements about their hypotheses and thus make more explicit comparisons than those provided by the NHST framework. The results highlighted by Figure 2 seem clear regarding the probability of each hypothesis. We will discuss these further. After examining the resulting posterior probabilities, the archaeologist determined that the Early period sample points were most probably used as arrows (with probability 0.97 ) and likely propelled by a bow-like mechanism. This mode of stone point propelling changed during the Late Period when the people living on this site began to use mainly hand-thrown spears (with probability 0.89$)$.

In this way, the Bayesian approach to testing hypotheses leads to results that are more readily interpreted than those via the p-value based NHST. In particular, we are provided with measures of probability that the data support the hypotheses, which have considerably more intuitive interpretation than those provided by p-values. 
Table 4 Posterior probabilities that the Early and Late Period maximum projectile point lengths were associated with arrow, dart, and spear propelling technologies.

\begin{tabular}{llll}
\hline Function & Mean \pm SD of max. point length & Early Period & Late Period \\
\hline Arrow & $6.9 \pm 2$ & 0.97 & 0.0009 \\
Dart Tips & $11 \pm 2$ & 0.004 & 0.17 \\
Spear Tips & $14 \pm 2$ & 0.00002 & 0.89 \\
\hline
\end{tabular}

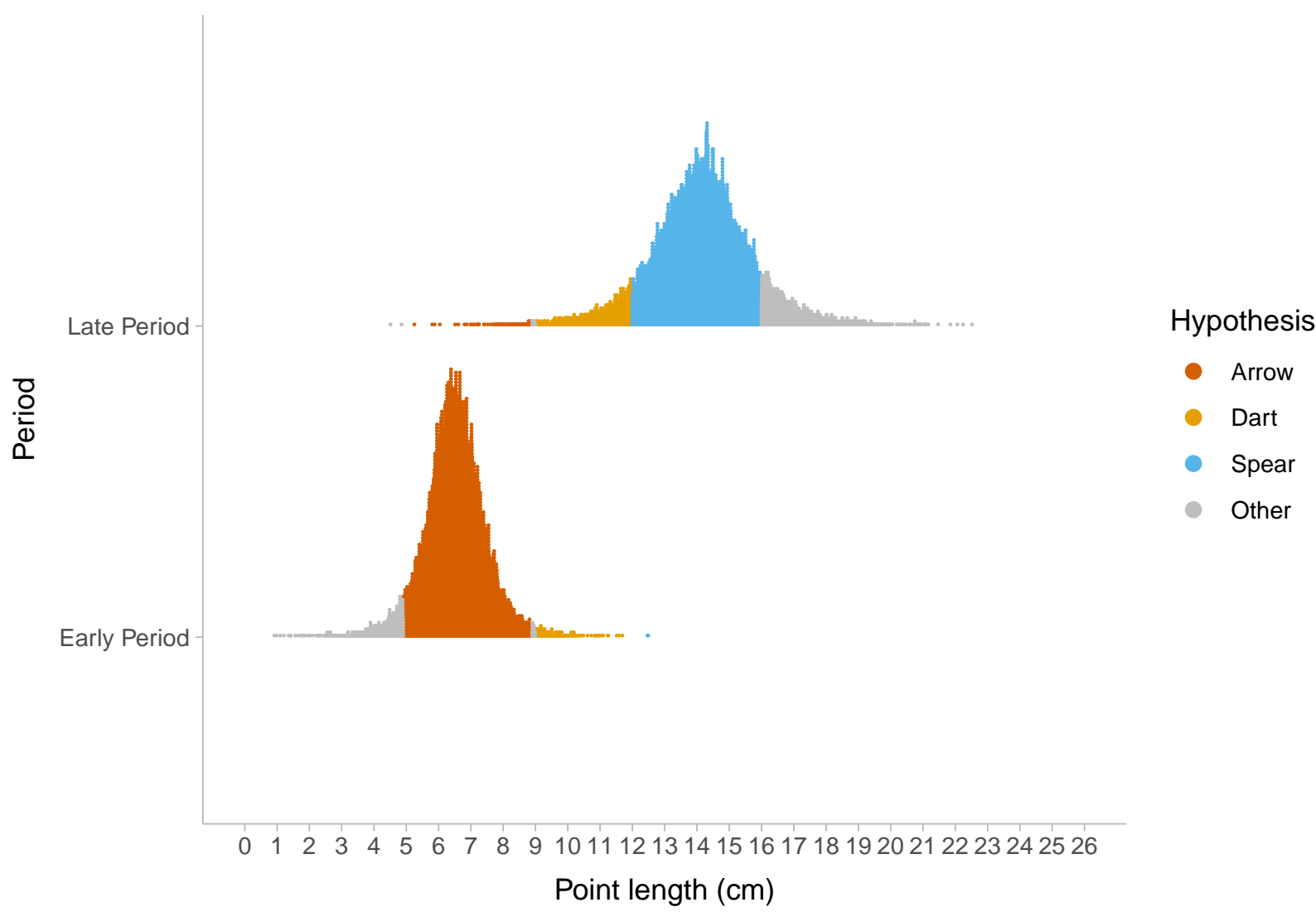

Figure 2: Bayesian posterior probability distributions of each of three propelling technology hypotheses: a) Arrow, b) Dart, c) Spear in the Early (bottom) and Late (top) periods. The amount of area under the curve reflects the probability of each hypothesis expressed as percentages. 


\section{WHAT IS BAYES' THEOREM}

Bayes' theorem is an algorithm for obtaining the value of a conditional probability statement, when one knows its inverse. It is usually exemplified by considering two related events, A and B. Put simply, Bayes' theorem states that (equation 1):

$$
P(A \mid B)=\frac{P(B \mid A) \cdot P(A)}{P(B)}
$$

In this case, to obtain the conditional probability of $\mathrm{A}$ given $\mathrm{B}, \mathrm{P}(\mathrm{A} \mid \mathrm{B})$ - here $\mathrm{P}$ represents probability and $\mid$ is read as 'given' - one needs to divide the joint probability of $\mathrm{A}$ and $\mathrm{B}, \mathrm{P}(\mathrm{A}$ and $\mathrm{B})$, by the marginal probability of $\mathrm{B}, \mathrm{P}(\mathrm{B})$. The product of $\mathrm{P}(\mathrm{B} \mid \mathrm{A})$ and $\mathrm{P}(\mathrm{A})$ is the joint probability $\mathrm{P}(\mathrm{A}$ and $\mathrm{B})$. The formula then generalizes to equation (2):

$$
P(A \mid B)=\frac{P(A \cap B)}{P(B)}
$$

where the joint probability is divided by the marginal $\mathrm{P}(\mathrm{B})$. Statisticians call $\mathrm{P}(\mathrm{A} \mid \mathrm{B})$ the posterior probability of $\mathrm{A}$ given $\mathrm{B}, \mathrm{P}(\mathrm{B} \mid \mathrm{A})$ the inverse conditional (or likelihood) of $\mathrm{B}$ given $\mathrm{A}$, and $\mathrm{P}(\mathrm{A})$ the prior probability of A.

\section{The link between Bayes' theorem, inference, data and hypotheses}

The simulated archaeological scenario above provided a tangible example of the different components of a Bayesian analysis, including an event's probability, the probability of one event given another, prior and posterior probabilities. Although the procedure here is specific to archaeological data, Bayes' theorem is a very general algorithm that is useful for a wide variety of data and data-generating processes. This section generalizes Bayes' theorem to a variety of other scenarios.

We stated earlier that Bayesian statistics uses the data in hand, (D), to assign probabilities to hypotheses about a population $(\mathrm{H})$. The statement $\mathrm{P}(\mathrm{H} \mid \mathrm{D})$, i.e., the probability of the hypothesis given the data, formalizes this relationship. To operationalize this statement in the context of data and hypotheses, Bayes' theorem functions as

$$
P(H \mid D)=\frac{P(D \mid H) \cdot P(H)}{P(D)}
$$

where: $\mathrm{P}(\mathrm{H} \mid \mathrm{D})$ is the posterior probability - the probability of the hypothesis given the data in hand; $\mathrm{P}(\mathrm{D} \mid \mathrm{H})$ is the probability of the data given the hypothesis, or the "likelihood" of the observed data; $\mathrm{P}(\mathrm{H})$ is the prior probability of the hypothesis (before the data were observed), and $\mathrm{P}(\mathrm{D})$ is the probability of the 
data in hand (out of all possible values of the data). Alternatively, using modern statistical vernacular this operation can then be expressed in a slightly different form as:

$$
\text { Posterior }=\frac{\text { Likelihood } \cdot \text { Prior }}{\text { P(Data })}
$$

In Otárola-Castillo and Torquato's artificial example, the hypotheses represented the belief that the observed Early and Late period projectile point data represented samples from populations derived from particular propelling technologies. The data were modelled by the Normal probability distribution, and the hypotheses were characterized by the values of the model's parameters.

We use the symbol $\mathrm{x}$ to represent the observed data and the symbol $\theta$ to represent the parameter(s) of our model of the population that we are trying to learn about. Given $\mathrm{x}$ and a model with parameter(s) $\theta$, we can more formally describe Bayes' theorem and its three components: the likelihood, the prior, and the posterior.

i. The likelihood is a statistical function. Its form is determined by the specific probability model we are using but, in general terms it is represented by $\mathrm{P}(\mathrm{x} \mid \theta)$. Consequently, the likelihood is the probability of observing particular data values given some specific values of the unknown parameters. Thus, this is a formal statement of the relationship between what we want to learn and the data we collect.

ii. The prior is also a function and can be represented by $\mathrm{P}(\theta)$. In simple terms, we can think of this as the probability we attach to observing specified values of the unknown parameters before (a priori) we observe the data. In other words, this is a formal statement of what we knew before the latest data were collected.

iii. The posterior is the probability distribution that we want to obtain (a combination of the information contained in the data, the likelihood and the prior) and can be represented by $\mathrm{P}(\theta \mid \mathrm{x})$. Put plainly, this is the probability we attach to specified values of the unknown parameters after observing the data. In this more technical context, we can express Bayes' theorem as:

$$
P(\theta \mid x)=\frac{P(x \mid \theta) \cdot P(\theta)}{P(x)}
$$

In addition, the numerator, the product of the likelihood and the prior probability without the normalizing denominator $\mathrm{P}(x)$ is proportional to $(\propto)$ the posterior and is often computed and expressed by

$$
P(\theta \mid x) \propto P(x \mid \theta) \cdot P(\theta)
$$


or,

In this manner, Bayesian statistics offers an alternative statistical framework for evaluating hypotheses through a mechanism for obtaining a posteriori information about the parameter values of interest, based upon the data, a model, and appropriately formulated prior information. In other words, given an explicit statement of our a priori information, a clearly defined statistical model and a desire to obtain $a$ posteriori understanding, Bayes' theorem provides us with a probabilistic framework within which to make interpretations.

In addition to the coherent and explicit nature of the framework, there is another attractive feature of adopting the Bayesian paradigm in that it allows us to learn from experience. Priors enable the explicit contextualization of previous knowledge or beliefs about the topic under investigation (George L. Cowgill 1993; Caitlin E. Buck, Cavanagh, and Litton 1996). This should be a natural feature to archaeologists for whom context is quite meaningful, or as Caitlin E. Buck, Cavanagh, and Litton (1996) discuss, archaeologists interpret the discovery of new artifacts in conjunction with artifacts that have already been discovered.

Moreover, today's posterior information (based on current data and prior information) is in a suitable form to become the prior for further work if and when more data become available. Few other interpretative frameworks offer a clear structure for updating one's beliefs in the light of new information and yet it is such an important part of most intuitive approaches to learning about the world in which we live. 


\section{OTHER ARCHAEOLOGICAL APPLICATIONS}

\section{Chronological modelling}

The reliable construction of chronologies is an integral part of all archaeological research. Consequently, an abundance of research has been conducted to create robust chronologies and thus, assist archaeologists in interpreting past events. Early work laid the foundation for the use of Bayesian methods in chronological modelling to improve precision (Naylor and Smith 1988; Caitlin E. Buck et al. 1991; Caitlin E. Buck, Litton, and Smith 1992). The advent and continued improvement of user-friendly modelling software, including BCal (Caitlin E. Buck, Christen, and James 1999) and OxCal (Bronk Ramsey 1994, 2017), has enabled many archaeologists to employ Bayesian chronological modelling in their research. In fact, the construction of chronologies has been described as the one archaeological application of Bayesian methods that is now routine (Caitlin E. Buck and Meson 2015).

There has been a documented increase in the use of Bayesian chronological modelling over the last decade (Bayliss 2015; Hamilton and Krus 2018), as numerous studies have re-examined radiocarbon dates to refine regional chronologies. Although these methods were initially used by archaeologists in the United Kingdom (Hamilton and Krus 2018), Bayesian chronological studies have now been conducted in nearly every region of archaeological interest, including:

i. Central America (Inomata et al. 2017; Mendelsohn 2018; Tsukamoto et al. 2020);

ii. South America (Erik J. Marsh et al. 2017; Wynveldt et al. 2017),

iii. Europe (Arvaniti and Maniatis 2018; Jiménez et al. 2018; Krajcarz et al. 2018; Manning et al. 2018; Ricci et al. 2018; Paulsson 2019),

iv. Asia (Long, Wagner, and Tarasov 2017; Ricci et al. 2018; Birch-Chapman and Jenkins 2019; Yang et al. 2019),

v. Africa (Kramer, Veile, and Otárola-Castillo 2016; Brandt et al. 2017; Sadr et al. 2017; Loftus, Mitchell, and Bronk Ramsey 2019), and

vi. Oceania (Brockwell et al. 2017; Kirch and Swift 2017; Urwin and Arifeae 2018; David et al. 2019).

Indeed, even those archaeologists who simply report individual, calibrated radiocarbon dates are now reliant on Bayesian methods since the most recent estimates of the radiocarbon calibration curves (IntCal20, SHCal20, and Marine20) are grounded in Bayesian inference. They were constructed using a Bayesian spline approach to combine data from tree rings, floating tree-ring chronologies, lacustrine and marine sediments, speleothems, and corals (Reimer et al. 2020).

Archaeologists have applied Bayesian methods to other methods of absolute dating. For example, recent 
studies have constructed chronological models using optically-stimulated luminescence (OSL) dates (Clarkson et al. 2017; Combès and Philippe 2017; Veth 2017; Jiménez et al. 2018; Demuro et al. 2019 ; Heydari et al. 2020), and dendrochronology (Millard 2002; Hassan, Jones, and Buck 2019; Lorentzen, Manning, and Cvikel $2020)$.

Perhaps most significantly, Bayesian chronological modelling enables archaeologists to include numerous sources of archaeological dates in a single interpretive framework, including those drawn from relative dating and absolute dating, to create chronologies of hard-to-date contexts. By combining relative dating and absolute dating methods with Bayesian modelling, archaeologists can produce more precise and accurate dates (George L. Cowgill 2015). For example, Croix et al. (2019) combined artifact chronologies, coin dates, and radiocarbon dating in a Bayesian model to date earthworks in Denmark. Prior to this research, dating these structures was difficult due to the limited survival of dateable artifacts and the reuse of building materials in antiquity. By constructing a Bayesian chronological model using coin age and radiocarbon dates, researchers improved the dating precision of the earthworks. Furthermore, DiNapoli et al. (2020) used a Bayesian modelling approach to combine radiocarbon dates, stratigraphy, and ethnohistoric accounts to examine the collapse and resilience of populations on Rapa Nui. Other examples of studies include those combining absolute dating methods (e.g., Anyon et al. 2017; Fitzsimmons et al. 2017; Smith, Williams, and Ross 2017) and those drawing on relative and absolute dating methods (e.g., Guérin et al. 2017; Douka et al. 2019).

Other studies have used Bayesian modelling to clarify the complex relationship between humans and the environment. For example, Banks and colleagues (2019) utilized Bayesian hierarchical modelling to determine the date for cultures from Upper Palaeolithic France. These dates were then compared to palaeoecological records to determine the palaeoclimatic variability during each period. Similarly, Kearney (2019) used Bayesian methods to combine archaeological and palaeoecological chronologies in a study examining the connection between vegetation changes and human activity near a megalithic tomb dating to the Neolithic in Ireland. Using this method, he was able to determine if significant palynological events occurred before, after or during the construction and use of the tomb. Ultimately, he determined that the clearing of the woodland occurred prior to the construction of the megalith.

\section{Artifact analysis}

Bayesian inference has been applied in numerous ways to study a broad array of artifacts, including ceramics, bone and stone tools. Early applications examined the provenance of artifacts and ceramic seriation (e.g.,

Caitlin E. Buck and Litton 1990; Caitlin E. Buck, Cavanagh, and Litton 1996; Halekoh and Vach 1999; Robertson 1999). Continued research examining ceramics has utilized Bayesian modelling of radiocarbon 
dates to determine the chronologies of ceramic artifacts by combining absolute dating and studies of ceramic typologies (e.g., Naylor and Smith 1988). Similar methods have been used to examine ceramic traditions in Europe (Krol, Dee, and Nieuwhof 2020), Bolivia (Erik J. Marsh et al. 2019), Guatemala (Arroyo et al. 2020), and Papua New Guinea (Skelly et al. 2018). The combination of chronological modelling and ceramic data has been used to examine the dispersal and spread of ceramic cultures (e.g., Méhault 2017; Binder et al. 2018).

Recently, the application of Bayesian modelling to ceramic analysis has extended beyond seriation. For example, Fernandes et al. (2018) used a Bayesian approach to identify the types of food that created residues in prehistoric European pottery. By analysing carbon isotope measurements and comparing them with measurements from known sources, the authors determined which foods had contributed to the residues and thus how the pots had been used. Since pots are reused to prepare multiple types of foods, results can be ambiguous when identifying the foods contributing to residues. The use of Bayesian methods addressed this ambiguity by estimating the contribution of various food types to the residues.

Furthermore, Bayesian methods are becoming integral in the study of stone and bone tools. Researchers have used Bayesian methods to test hypotheses about stone tool assemblages (e.g., Marwick et al. 2016) and develop techniques for studying stone tools. These techniques allow researchers to assign probabilities to the phenomenon being studied. For example, Murray et al. (2020) developed a novel method combining 3D microscopic analyses of surface roughness and a Bayesian probability model to evaluate if Middle Stone Age silcrete tools from Pinnacle Point 13B (South Africa) had been heat treated. The model measured the probability that a tool has been heat treated,allowed for the continued updating from future heat treatment experiments, and performed with high accuracy. Similarly, other researchers combined a taphonomic analysis of the surface of unworked bone and bone tools with multivariate Bayesian modelling to quantify the taphonomic changes on the surfaces of the unworked and worked bones to accurately predict the original surface of the bone tools (Martisius et al. 2018, 2020).

\section{Zooarchaeology}

Researchers have used Bayesian statistics to study zooarchaeological trends. Pioneering work by D. C. Fisher (1987) used Bayesian inference to determine whether scavenging or hunting led to the creation of butchery marks on proboscidean assemblages. Recent work has focused on studying seasonality and domestication. For example, Parkington et al. (2020) used a Bayesian approach to study the seasonal use of Later Stone Age archaeological sites in South Africa. By reanalysing their previous studies on the timing of death using a Bayesian framework, they were able to determine, with greater accuracy, when hunter-gatherers would have used the sites where seal remains were found. Additionally, scholars have used Bayesian methods to 
construct phylogenies examining the domestication of animals, including swamp buffalo (Wang et al. 2017) and pigs (Xiang et al. 2017). Other research has examined the foods consumed by domesticated animals. Blanz et al. (2020) used Bayesian modelling to examine the diets of modern sheep, specifically the amount of seaweed consumed, which can be used as a reference sample for identifying similar consumption patterns in archaeological contexts.

Additionally, archaeologists have used Bayesian methods to study faunal assemblages and make inferences about their use. For example, Osborn (2019) constructed a Bayesian network model using ethnographic, ethnohistoric, and archaeological data to determine whether Andean faunal assemblages indicated feasting, sacrifice, or daily refuse. The primary benefit of using a Bayesian approach in the study was the resulting replicable analysis that eliminates the subjectivity present in interpreting faunal assemblages. Rather, this method reports the probabilities of the faunal assemblage representing each type of behaviour. Furthermore, Baumann et al. (2020) used Bayesian methods to estimate the abundance of foxes and hares in Palaeolithic Europe to determine how their abundance changed over time as they were hunted by humans for their meat, fur, and teeth. The use of Bayesian methods in this study allowed the researchers to overcome a small sample size while modelling animal abundance.

Bayesian techniques have been used to develop and re-examine the methods used in zooarchaeological research. Researchers have used Bayesian inference to develop a reliable and replicable probabilistic method to distinguish between sheep and goat bones in archaeological contexts (Wolfhagen and Price 2017). Since goats and sheep are very similar species that share many traits, it can be difficult to distinguish between them. This method provides the probability that a specimen is a goat given the identified traits. Furthermore, Wolfhagen (2020) has re-examined the "logarithm size index" (LSI), a method for comparing the body sizes of animals between assemblages that is typically used in studies of animal domestication. He suggests adopting Bayesian multilevel LSI models to examine hypotheses about faunal assemblages.

\section{Bioarchaeology}

The use of Bayesian methods in bioarchaeological analyses was pioneered by Konigsberg and colleagues for studying age-at-death and stature estimation (e.g., Lyle W. Konigsberg and Frankenberg 1992 ; Lyle W. Konigsberg and Frankenberg 1994; Lucy et al. 1996; Lyle W. Konigsberg et al. 1998). Recent research has continued to apply Bayesian statistics to the construction of biological profiles. For example, Anzellini and Toyne (2019) proposed the use of Bayesian logistic regression to account for uncertainty in the sample when estimating the sex of individuals found in commingled contexts in the Andes. Although the frequentist and Bayesian approaches produced similar results, the authors demonstrated the validity of using Bayesian methods to account for uncertainty and to produce usable demographic profiles in bioarchaeological studies. 
Furthermore, Rosenstock et al. (2019) used Bayesian additive mixed modelling to examine the global spatiotemporal trend in stature. This method enabled the researchers to account for spatiotemporally patchy data as well as fragmentary skeletal samples.

Further studies have utilized Bayesian mixing models to reconstruct prehistoric diets. Typically, these methods have used carbon and nitrogen stable isotope data to determine the types of foods people were eating. One popular method is called the Food Reconstruction Using Isotopic Transferred Signals (FRUITS) approach, which can account for multiple dietary sources and the uncertainty inherent in dietary inference. For example, Pezo-Lanfranco et al. (2018) used Bayesian mixing models to quantify the proportion of three sources of food: plants, marine mammals, and terrestrial mammals. They determined that the people of the Atlantic Forest of South America consumed a large amount of carbohydrates, suggesting a unique diet compared to other populations in the area during the Middle Holocene. Using various Bayesian mixing models, other studies have examined prehistoric dietary trends in Europe (Bownes et al. 2017; sjogren_modelling_2017?; Boethius and Ahlström 2018; Cubas et al. 2019), South America (Gordón et al. 2018), and Africa (Maurer et al. 2017). Recent studies have used similar Bayesian modelling to study prehistoric weaning trends (King et al. 2017). Specifically, using the FRUITS method, De Angelis et al. (2020) reconstructed the diet of those buried at the Quarto Cappello del Prete. From this reconstruction, they determined that Roman children were weaned around three years of age.

Other researchers have used mixed/multilevel/hierarchical modelling approaches. For example, Perri et al. (2019) examined the canine diet as a proxy for human diets in archaeological contexts in Nicaragua. To infer the probability of the model's parameters the authors used a Bayesian approach including MCMC to estimate the denominator of Bayes theorem. Hierarchical models in this context are flexible and scalable (Gelman and Hill 2006). They can include individual and group level data in a model. This flexibility provides improved inference on the parameters in question, resulting in more accurate estimates of the model's parameters (Katahira 2016).

\section{Spatial archaeology}

By combining prior knowledge regarding geographical data, archaeologists have been able to study spatial trends (see Chapter xx). For example, researchers have used Bayesian methods to examine the placement of archaeological sites on the landscape (Wright, MacEachern, and Lee 2014) and predict the locations and settlement patterns of archaeological sites (Ortman, Varien, and Gripp 2007; Stewart et al. 2017). Other research has incorporated Bayesian chronological modelling into spatial archaeological analyses. For example, Snitker et al. (2018) combined prehistoric land use maps generated by surveys, chronological data, and Bayesian methods to examine shifting occupation and land use patterns in Spain. The use of Bayesian 
methods in this study was critical as it allowed the researchers to make probabilistic inferences regarding the most likely occupation period at archaeological sites that may have been reused throughout history. Similarly, Wright et al. (2020) used Bayesian chronological modelling of radiocarbon dates to construct a summed probability distribution estimating occupation events in the Baekje Kingdom of Korea during the Three Kingdoms Period (57 BCE to $688 \mathrm{CE}$ ). The researchers proceeded to use these data as part of a larger model examining the spatial distribution and dynamics of human activity areas over time. These methods allowed the researchers to make probabilistic statements about settlement patterns' hypotheses at a time when occupation patterns were thought to be changing. 


\section{SOME PRACTICALITIES}

\section{Modelling}

Although numerous probability models exist, many archaeological problems are statistically non-standard. This has often meant that the close collaboration of a number of specialists, including statisticians, is required to build useful models. Fortunately, statisticians have often found archaeological problems to be interesting and challenging and so this kind of collaboration is not too unusual. Nonetheless, although applications of Bayesian analysis to archaeology have been around for more than 30 years, they are by no means ubiquitous and further collaboration is certainly needed.

\section{Specifying the prior}

One of the major stumbling blocks to the more widespread use of Bayesian techniques in archaeology is the perceived difficulty of specifying prior information. Some archaeologists do not acknowledge that reliable prior information exists and others have philosophical objections to the use of subjective opinions in formal inference. Both such groups typically prefer to continue using exploratory methods or traditional NHSTbased ones. Others have expert knowledge and would like to use it, but have difficulty expressing their ideas in a suitable form because of their lack of knowledge about the mathematics that underlie the models they wish to use. Tackling this problem requires further collaboration, clear communication, and an acceptance that different researchers will have varying views on which interpretive framework to use or which specific model to adopt. Most importantly, there is no need for everyone to agree. Researchers who adopt the Bayesian framework are forced to be explicit about what they believe. As a result, different workers can compute posteriors based on their own prior information and compare them formally with the inferences of others.

\section{Evaluating the posteriors}

Early applications of the Bayesian framework to archaeology (as with other disciplines) were restricted to likelihoods and priors for which the necessary calculations could easily be undertaken. However, since the mathematical integrations required for some models are not analytically soluble, a fair number of real questions simply could not be tackled. These problems have now largely been overcome by the widespread adoption of numerical techniques that allow the posterior information to be sampled rather than obtained exactly. Some of the earliest illustrations of the use of these techniques for evaluating Bayesian posteriors were in Bayesian radiocarbon calibration (Caitlin E. Buck, Litton, and Smith 1992; Caitlin E. Buck, Christen, and James 1999; Litton and Buck 1996). Advances in algorithms to create and sample from Markov 
chain Monte Carlo simulations (MCMC) such as Metropolis-Hastings, Gibbs sampling, and the Hamiltonian procedures such as No U-Turn Sampling (NUTS) (e.g., Dunson and Johndrow 2020; Hoffman and Gelman 2014) implemented by popular software like BUGS, JAGS, and STAN (Gilks, Thomas, and Spiegelhalter 1994; Plummer 2003; Sturtz, Ligges, and Gelman 2005; Team 2019) have helped to alleviate this problem.

\section{Interpretation}

Ultimately, the most important part of any statistical investigation is the interpretation of the results obtained. The posterior distributions that arise from Bayesian analyses can be very complex and are sometimes not directly interpretable in terms of the original problem. This means that exploratory methods of data analysis may be needed to help investigate, interpret, and report upon the posterior distributions obtained. When making such interpretations, the level of confidence in the posteriors is affected by their sensitivity to changes in the data, priors, or model. Such sensitivity should be investigated as part of the interpretation of all posterior information. It is always useful to relax some of the prior assumptions and re-compute the posteriors to see what effect this has. All reports of Bayesian analyses should make reference to sensitivity analyses of this type, since without them we cannot be sure how robust the results are and thus how reliable they would be as prior information for future research. 


\section{HOPES FOR THE FUTURE}

We have discussed the positive contributions of Bayesian inference to archaeological thinking. In addition to providing a fully probabilistic framework, Bayesian statistics requires that one makes existing prior knowledge explicit to use in statistical analyses. By doing so, scientists take advantage of a more comprehensive set of information when evaluating hypotheses. This is a major advantage over NHST and the related Maximum Likelihood, and Information Theory approaches to model-selection (Murtaugh 2014). Increases in the popularity of Bayesian applications in archaeology are likely due to the recognition of these features. To continue this trend, we outline an ambitious set of initiatives we hope to see in the future of Bayesian applications in archaeology.

\section{A framework for archaeological science}

The Bayesian approach provides a systematic learning procedure, using evidence to update one's beliefs or hypotheses until reaching a confident and accurate level of knowledge. This evidence-based learning approach inherently resembles the scientific process of hypothesis generation and evaluation. As a science, data-laden inference about the past is also inherent to archaeology. New knowledge from archaeological data recovery through excavation, survey, or analytical activities constantly update archaeologists' state of knowledge and revise the degree of support for prior hypotheses (e.g., the initial colonization of the Americas and out of Africa origins of Homo sapiens).

\section{Increase diversity of Bayesian applications}

Gauging by the seemingly exponential increase in the number of Bayesian papers in archaeology in the 2000s to the 2010s (Otárola-Castillo and Torquato 2018, Fig 1), not only has the Bayesian inferential framework increased in popularity in the general sciences, but also in archaeology. This jump in usage is also evidenced by the number of Bayesian papers, posters, and symposia at conferences (e.g., C. Buck, Dye, and May 2020; Krus and Barkwill Love 2020; Wolfhagen and Otárola-Castillo 2021).

The increase in applications is due in part to purpose-written software and libraries, tailored to the needs of archaeologists (e.g., OxCal, BCal, and Bchron (Haslett and Parnell 2008)). Increasingly, however, as archaeologists become more confident to write their own code, simple-to-use and accessible software like STAN, JAGS, and BUGS (Gilks, Thomas, and Spiegelhalter 1994; Plummer 2003; Sturtz, Ligges, and Gelman 2005; Team 2019) are also being adopted. For R users, for example, the RStan package (Team 2020) has simplified the access to this software, and so has the development of "higher level" code R-packages like Rstanarm and BRMS (Bürkner 2017; Goodrich et al. 2020). 


\section{Training in underlying theory}

With accessibility, however, there is potential for technical sophistication and attention to detail to be missed. Adopting easy-to-access software might hide some of the Bayesian approach's complexity, comprehension of which is necessary in order for users to take responsibility for the modelling choices inherent in adopting them.

As such, one of our hopes for the future is an increase in training opportunities for archaeologists in both the statistical and theoretical details underlying Bayesian inference, and the technical and practical details associated with implementation. In our opinion, greater knowledge of these two steps will generate a deeper understanding and more responsible adoption of the Bayesian framework for inference.

This leads to the type of student training we hope to see in the future. Training students to become aware of and fluent in the theory underlying NHST and Bayesian inference will need some remodelling to current curricula. Integrating statistical and computational theory into archaeological study programs would be one step towards providing students with the expertise to evaluate and develop reliable Bayesian solutions for themselves. It would, of course, also allow them to evaluate more responsibly the modelling work of others, thus leading to a better informed and more articulate body of reviewers for archaeological journals.

\section{The power of algorithmic thinking}

Training in probability theory and coding alone will not change a discipline, but together with an encouragement to formalize thinking they might. Archaeologists are widely known for our meticulous record keeping. We propose that archaeologists complement our reputation for high quality documentation, by adding greater formalization to our thinking and hypothesizing. Coders do this out of necessity, but it is not routine practice in most of archaeology.

There are, of course, widely used and highly regarded field manuals that encourage step-by-step recordkeeping (Center 2001; Hester, Shafer, and Feder 2016; White and King 2016) and many modern excavations follow these closely. . However, beyond fieldwork, careful data handling and modelling procedures have traditionally not been given such emphasis, although there are, and have been, notable examples of good practice (e.g., Carlson 2017; McCall 2018; Banning 2020). Processes such as phasing a site or interpretation of the archaeological record in an entire landscape, require the handling of very large amounts of information, typically held in many different computer files. The field would benefit if this processing were systematically recorded and replicable. The consequence of not doing this might be an undocumented workflow that even those involved struggle to fully recreate if needed.

Those with coding experience know that poorly documented workflows are not a sustainable approach 
to information management. What's needed instead is a step-by-step or flow-diagram approach to planning and documenting the post-excavation workflow. Setting up such approaches is time-consuming, of course, but the advantages for reproducibility are immeasurable. Fortunately, archaeologists are increasingly open to adopting some of these processes (Marwick 2017). Moreover, there are now several well-established environments that encourage researchers to take this approach. One such is Rmarkdown (Allaire et al. 2020) which allows users to embed $\mathrm{R}$ code and output within a text document. Those of us who use such environments have found that we naturally document the data management and analysis process, as we work, and can write up and archive our work much more quickly and accurately, too. 


\section{REFERENCES}

Allaire, J, Yihui Xie, Jonathan McPherson, Javier Luraschi, Kevin Ushey, Aron Atkins, Hadley Wickham, Joe Cheng, Winston Chang, and Richard Iannone. 2020. "Rmarkdown: Dynamic Documents for R." $R$ Package. Available: URL Https://Rmarkdown.rstudio.com. rmarkdown.rstudio.com.

Anyon, Roger, Darrell Creel, Patricia A Gilman, Steven A LeBlanc, Myles R Miller, Stephen E Nash, Margaret C Nelson, Kathryn J Putsavage, Barbara J Roth, and Karen Gust Schollmeyer. 2017. "ReEvaluating the Mimbres Region Prehispanic Chronometric Record.” Kiva 83 (3): 316-43.

Anzellini, Armando, and J Marla Toyne. 2019. "Estimating Sex Using Isolated Appendicular Skeletal Elements from Chachapoyas, Peru." International Journal of Osteoarchaeology 29 (6): 961-73.

Arroyo, Bárbara, Takeshi Inomata, Gloria Ajú, Javier Estrada, Hiroo Nasu, and Kazuo Aoyama. 2020. "Refining Kaminaljuyu Chronology: New Radiocarbon Dates, Bayesian Analysis, and Ceramics Studies." Latin American Antiquity 31 (3): 477-97.

Arvaniti, Theodora, and Yannis Maniatis. 2018. "Tracing the Absolute Time-Frame of the Early Bronze Age in the Aegean." Radiocarbon 60 (3): 751.

Banning, Edward B. 2020. The Archaeologist's Laboratory: The Analysis of Archaeological Evidence. 2nd ed. New York: Springer International Publishing. https://doi.org/10.1007/978-3-030-47992-3.

Baumann, Chris, Gillian L Wong, Britt M Starkovich, Susanne C Münzel, and Nicholas J Conard. 2020. "The Role of Foxes in the Palaeolithic Economies of the Swabian Jura (Germany)." Archaeological and Anthropological Sciences 12 (9): 1-17.

Bayes, Thomas. 1763. "An Essay Towards Solving a Problem in the Doctrine of Chances." Philosophical Transactions 53: 370-418.

Bayliss, Alex. 2015. "Quality in Bayesian Chronological Models in Archaeology." World Archaeology 47 (4): $677-700$.

Bellhouse, David R. 2004. "The Reverend Thomas Bayes, FRS: A Biography to Celebrate the Tercentenary of His Birth." Statistical Science 19 (1): 3-43.

Benjamin, Daniel J, and James O Berger. 2019. "Three Recommendations for Improving the Use of pValues." The American Statistician 73 (sup1): 186-91.

Binder, Didier, Philippe Lanos, Lucia Angeli, Louise Gomart, Jean Guilaine, Claire Manen, Roberto Maggi, Italo M Muntoni, Chiara Panelli, and Giovanna Radi. 2018. "Modelling the Earliest North-Western Dispersal of Mediterranean Impressed Wares: New Dates and Bayesian Chronological Model." Documenta Praehistorica. 44: 54-77.

Binford, Lewis R. 1964. "A Consideration of Archaeological Research Design." American Antiquity, 425-41. 
Birch-Chapman, Shannon, and Emma L Jenkins. 2019. "A Bayesian Approach to Calculating Pre-Pottery Neolithic Structural 1 Contemporaneity for Reconstructing Population Size." Journal of Archaeological Science 112 (December).

Blanz, Magdalena, Ingrid Mainland, Michael Richards, Marie Balasse, Philippa Ascough, Jesse Wolfhagen, Mark A Taggart, and Jörg Feldmann. 2020. "Identifying Seaweed Consumption by Sheep Using Isotope Analysis of Their Bones and Teeth: Modern Reference 13C and 15N Values and Their Archaeological Implications." Journal of Archaeological Science 118: 105140.

Boethius, Adam, and Torbjörn Ahlström. 2018. "Fish and Resilience Among Early Holocene Foragers of Southern Scandinavia: A Fusion of Stable Isotopes and Zooarchaeology Through Bayesian Mixing Modelling." Journal of Archaeological Science 93: 196-210.

Bownes, Jessica M, Philippa L Ascough, Gordon T Cook, Iona Murray, and Clive Bonsall. 2017. "Using Stable Isotopes and a Bayesian Mixing Model (FRUITS) to Investigate Diet at the Early Neolithic Site of Carding Mill Bay, Scotland." Radiocarbon 59 (5): 1275-94.

Brandt, Steven, Elisabeth Hildebrand, Ralf Vogelsang, Jesse Wolfhagen, and Hong Wang. 2017. "A New MIS 3 Radiocarbon Chronology for Mochena Borago Rockshelter, SW Ethiopia: Implications for the Interpretation of Late Pleistocene Chronostratigraphy and Human Behavior." Journal of Archaeological Science: Reports 11: 352-69.

Brockwell, Sally, BILLY Ó FOGHLÚ, Jack N Fenner, Janelle Stevenson, Ulrike Proske, and Justin Shiner. 2017. "New Dates for Earth Mounds at Weipa, North Queensland, Australia." Archaeology in Oceania $52(2): 127-34$.

Bronk Ramsey, Christopher. 1994. "Analysis of Chronological Information and Radiocarbon Calibration: The Program OxCal." Archaeological Computing Newsletter 41 (11): e16.

—. 2017. "Methods for Summarizing Radiocarbon Datasets." Radiocarbon 59 (6): 1809-33.

Buck, Caitlin E. 2001. Applications of the Bayesian Statistical Paradigm.

Buck, Caitlin E., and Bo Meson. 2015. "On Being a Good Bayesian." World Archaeology 47 (4): 567-84. https://doi.org/10.1080/00438243.2015.1053977.

Buck, Caitlin E, William G Cavanagh, and Cliff D Litton. 1996. Bayesian Approach to Interpreting Archaeological Data. New York: Wiley.

Buck, Caitlin E, J Andrés Christen, and Gary N James. 1999. "BCal: An on-Line Bayesian Radiocarbon Calibration Tool." Internet Archaeology 7.

Buck, Caitlin E, James B Kenworthy, Cliff D Litton, and Adrian Frederick Melhuish Smith. 1991. "Combining Archaeological and Radiocarbon Information: A Bayesian Approach to Calibration." Antiquity 65 (249): 808-21. 
Buck, Caitlin E, and Clifford D Litton. 1990. "A Computational Bayes Approach to Some Common Archaeological Problems." In Computer Applications and Quantitative Methods in Archaeology, BAR International Series, edited by K Lockyear and S Rahtz, 565:93-99. Oxford.

Buck, Caitlin E, Clifford D Litton, and Adrian FM Smith. 1992. "Calibration of Radiocarbon Results Pertaining to Related Archaeological Events." Journal of Archaeological Science 19 (5): 497-512.

Buck, Caitlin, Thomas Dye, and Keith May. 2020. "Stratification and Correlation: Tools and Techniques for Archaeological Chronology (Symposium)." In Society for American Archaeology 85th Annual Meeting.

Bürkner, Paul-Christian. 2017. "Brms: An R Package for Bayesian Multilevel Models Using Stan." Journal of Statistical Software 80 (1): 1-28.

Carlson, David L. 2017. Quantitative Methods in Archaeology Using R. Cambridge, UK/New York: Cambridge University Press.

Center, Crow Canyon Archaeological. 2001. "The Crow Canyon Archaeological Center Field Manual." http://www.crowcanyon.org/fieldmanual.

Clarke, David L. 1968. Analytical Archaeology. London: Methuen.

Clarkson, Chris, Zenobia Jacobs, Ben Marwick, Richard Fullagar, Lynley Wallis, Mike Smith, Richard G Roberts, Elspeth Hayes, Kelsey Lowe, and Xavier Carah. 2017. "Human Occupation of Northern Australia by 65,000 Years Ago." Nature 547 (7663): 306-10.

Combès, Benoit, and Anne Philippe. 2017. "Bayesian Analysis of Individual and Systematic Multiplicative Errors for Estimating Ages with Stratigraphic Constraints in Optically Stimulated Luminescence Dating." Quaternary Geochronology 39: 24-34.

Cowgill, George L. 1993. "Distinguished Lecture in Archeology: Beyond Criticizing New Archeology." American Anthropologist 95 (3): 551-73. http://www.jstor.org/stable/679650.

Cowgill, George L. 2001. "Past, Present, and Future of Quantitative Methods in United States Archaeology." In Computing Archaeology for Understanding the Past. CAA 2000. Computer Applications and Quantitative Methods in Archaeology, edited by Z Stančič and T Veljanovski, 35-40. Oxford, UK: Archaeopress.

—. 2015. "We Need Better Chronologies: Progress in Getting Them." Latin American Antiquity 26 (1): $26-29$.

Croix, Sarah, Olav Elias Gundersen, Søren M Kristiansen, Jesper Olsen, Søren M Sindbæk, and Morten Søvsø. 2019. "Dating Earthwork Fortifications: Integrating Five Dating Methods in Viking-Age Ribe, Denmark." Journal of Archaeological Science: Reports 26: 101906.

Cubas, Miriam, Rita Peyroteo-Stjerna, Maria Fontanals-Coll, Laura Llorente-Rodr guez, Alexandre Lucquin, Oliver Edward Craig, and André Carlo Colonese. 2019. "Long-Term Dietary Change in Atlantic and 
Mediterranean Iberia with the Introduction of Agriculture: A Stable Isotope Perspective." Archaeological and Anthropological Sciences 11 (8): 3825-36. https://doi.org/10.1007/s12520-018-0752-1.

David, Bruno, Jean-Jacques Delannoy, Fiona Petchey, Robert Gunn, Jillian Huntley, Peter Veth, Kim Genuite, Robert J Skelly, Jerome Mialanes, and Sam Harper. 2019. "Dating Painting Events Through by-Products of Ochre Processing: Borologa 1 Rockshelter, Kimberley, Australia." Australian Archaeology 85 (1): $57-94$.

De Angelis, Flavio, Virginia Veltre, Sara Varano, Marco Romboni, Sonia Renzi, Stefania Zingale, Paola Ricci, Carla Caldarini, Stefania Di Giannantonio, and Carmine Lubritto. 2020. "Dietary and Weaning Habits of the Roman Community of Quarto Cappello Del Prete (Rome, 1st-3rd Century CE)." Environmental Archaeology, 1-15.

Demuro, Martina, Leej Arnold, Nigel A Spooner, Kane Ditchfield, and Peter Veth. 2019. "Corrigendum: Coastal Occupation Before the 'Big Swamp': Results from Excavations at John Wayne Country Rockshelter on Barrow Island." Archaeology in Oceania 54 (1): 68-72.

Diez, David M, Christopher D Barr, and Mine Cetinkaya-Rundel. 2019. OpenIntro Statistics. OpenIntro. DiNapoli, Robert J, Timothy M Rieth, Carl P Lipo, and Terry L Hunt. 2020. "A Model-Based Approach to the Tempo of 'Collapse': The Case of Rapa Nui (Easter Island)." Journal of Archaeological Science, 105094.

Douka, Katerina, Viviane Slon, Zenobia Jacobs, Christopher Bronk Ramsey, Michael V Shunkov, Anatoly P Derevianko, Fabrizio Mafessoni, Maxim B Kozlikin, Bo Li, and Rainer Grün. 2019. "Age Estimates for Hominin Fossils and the Onset of the Upper Palaeolithic at Denisova Cave." Nature 565 (7741): 640-44. Dunson, David B, and JE Johndrow. 2020. "The Hastings Algorithm at Fifty." Biometrika 107 (1): 1-23. Fernandes, Ricardo, Yvette Eley, Marek Brabec, Alexandre Lucquin, Andrew Millard, and Oliver E Craig. 2018. "Reconstruction of Prehistoric Pottery Use from Fatty Acid Carbon Isotope Signatures Using Bayesian Inference." Organic Geochemistry 117: 31-42.

Fisher, Daniel C. 1987. "Mastodont Procurement by Paleoindians of the Great Lakes Region: Hunting or Scavenging?" In The Evolution of Human Hunting, 309-421. Springer.

Fisher, Ronald Aylmer. 1925. Statistical Methods for Research Workers. Edinburgh/London: Oliver; Boyd. Fitzsimmons, Kathryn E, Radu Iovita, Tobias Sprafke, Michelle Glantz, Sahra Talamo, Katharine Horton, Tyler Beeton, Saya Alipova, Galymzhan Bekseitov, and Yerbolat Ospanov. 2017. "A Chronological Framework Connecting the Early Upper Palaeolithic Across the Central Asian Piedmont." Journal of Human Evolution 113: 107-26.

Fletcher, Mike, and Gary R Lock. 2005. Digging Numbers: Elementary Statistics for Archaeologists. Oxford, UK: Oxford Press. 
Gelman, Andrew. 2006. "Multilevel (Hierarchical) Modeling: What It Can and Cannot Do." Technometrics 48 (3): 432-35. https://doi.org/10.1198/004017005000000661.

- 2018. "The Failure of Null Hypothesis Significance Testing When Studying Incremental Changes, and What to Do about It." Personality and Social Psychology Bulletin 44 (1): 16-23.

Gelman, Andrew, John B Carlin, Hal S Stern, David B Dunson, Aki Vehtari, and Donald B Rubin. 2020. Bayesian Data Analysis. Chapman; Hall/CRC press.

Gelman, Andrew, and Jennifer Hill. 2006. Data Analysis Using Regression and Multilevel/Hierarchical Models. Cambridge university press.

Gilks, Wally R, Andrew Thomas, and David J Spiegelhalter. 1994. "A Language and Program for Complex Bayesian Modelling." Journal of the Royal Statistical Society: Series D (The Statistician) 43 (1): 169-77.

Goodrich, Ben, Jonah Gabry, Imad Ali, and Sam Brilleman. 2020. "Rstanarm: Bayesian Applied Regression Modeling via Stan.” R Package Version 2.21.1. https://mc-stan.org/rstanarm.

Gordón, Florencia, S Ivan Perez, Adam Hajduk, Maximiliano Lezcano, and Valeria Bernal. 2018. "Dietary Patterns in Human Populations from Northwest Patagonia During Holocene: An Approach Using Binford's Frames of Reference and Bayesian Isotope Mixing Models." Archaeological and Anthropological Sciences 10 (6): 1347-58.

Guérin, Gilles, Pierre Antoine, Esther Schmidt, Emilie Goval, David Hérisson, Guillaume Jamet, JeanLouis Reyss, Qingfeng Shao, Anne Philippe, and Marie-Anne Vibet. 2017. "Chronology of the Upper Pleistocene Loess Sequence of Havrincourt (France) and Associated Palaeolithic Occupations: A Bayesian Approach from Pedostratigraphy, OSL, Radiocarbon, TL and ESR/U-Series Data." Quaternary Geochronology 42: 15-30.

Halekoh, UU, and Werner Vach. 1999. "Bayesian Seriation as a Tool in Archaeology." In Archaeology in the Age of the Internet, edited by L Dingwall, S Exon, V Gaffney, S Laflin, and M. van Leusen, 750:107-7.

Hamilton, W Derek, and Anthony M Krus. 2018. "The Myths and Realities of Bayesian Chronological Modeling Revealed." American Antiquity 83 (2): 187-203.

Haslett, John, and Andrew Parnell. 2008. "A Simple Monotone Process with Application to RadiocarbonDated Depth Chronologies." Journal of the Royal Statistical Society: Series C (Applied Statistics) 57 (4): 399-418. https://doi.org/https://doi.org/10.1111/j.1467-9876.2008.00623.x.

Hassan, Masoud M, E Jones, and Caitlin E Buck. 2019. "A Simple Bayesian Approach to Tree-ring Dating." Archaeometry 61 (4): 991-1010.

Hester, Thomas R, Harry J Shafer, and Kenneth L Feder. 2016. Field Methods in Archaeology. Routledge. Heydari, Maryam, Guillaume Guérin, Sebastian Kreutzer, Guillaume Jamet, Mohammad Akhavan Kharazian, Milad Hashemi, Hamed Vahdati Nasab, and Gilles Berillon. 2020. "Do Bayesian Methods 
Lead to More Precise Chronologies?'BayLum'and a First OSL-Based Chronology for the Palaeolithic Open-Air Site of Mirak (Iran)." Quaternary Geochronology, 101082.

Hoffman, Matthew D, and Andrew Gelman. 2014. "The No-U-Turn Sampler: Adaptively Setting Path Lengths in Hamiltonian Monte Carlo.” J. Mach. Learn. Res. 15 (1): 1593-623.

Howson, Colin, and Peter Urbach. 2006. Scientific Reasoning: The Bayesian Approach. Open Court Publishing.

Inomata, Takeshi, Daniela Triadan, Jessica MacLellan, Melissa Burham, Kazuo Aoyama, Juan Manuel Palomo, Hitoshi Yonenobu, Flory Pinzón, and Hiroo Nasu. 2017. "High-Precision Radiocarbon Dating of Political Collapse and Dynastic Origins at the Maya Site of Ceibal, Guatemala." Proceedings of the National Academy of Sciences 114 (6): 1293-98.

Jiménez, Gonzalo Aranda, Águeda Lozano Medina, Marta Díaz-Zorita Bonilla, Margarita Sánchez Romero, and Javier Escudero Carrillo. 2018. "Cultural Continuity and Social Resistance: The Chronology of Megalithic Funerary Practices in Southern Iberia." European Journal of Archaeology 21 (2): 192-216.

Katahira, Kentaro. 2016. "How Hierarchical Models Improve Point Estimates of Model Parameters at the Individual Level." Journal of Mathematical Psychology 73: 37-58. https://doi.org/https://doi.org/10. 1016/j.jmp.2016.03.007.

Kearney, Kevin. 2019. "Vegetation Impacts and Early Neolithic Monumentality: A Palaeoenvironmental Case Study from South-West Ireland." Journal of Archaeological Science: Reports 27: 101940.

King, Charlotte L, Andrew R Millard, Darren R Gröcke, Vivien G Standen, Bernardo T Arriaza, and Siân E Halcrow. 2017. "A Comparison of Using Bulk and Incremental Isotopic Analyses to Establish Weaning Practices in the Past." STAR: Science 83 Technology of Archaeological Research 3 (1): 126-34.

Kirch, Patrick V, and Jillian A Swift. 2017. "New AMS Radiocarbon Dates and a Re-Evaluation of the Cultural Sequence of Tikopia Island, Southeast Solomon Islands." Journal of the Polynesian Society, The 126 (3): 313.

Konigsberg, Lyle W., and Susan R. Frankenberg. 1994. "Paleodemography: 'Not Quite Dead'” Evolutionary Anthropology: Issues, News, and Reviews 3 (3): 92-105. https://doi.org/https://doi.org/10.1002/evan. 1360030306.

Konigsberg, Lyle W., Samantha M. Hens, Lee Meadows Jantz, and William L. Jungers. 1998. "Stature Estimation and Calibration: Bayesian and Maximum Likelihood Perspectives in Physical Anthropology." American Journal of Physical Anthropology 107 (S27): 65-92. https://doi.org/https://doi.org/10.1002/ (SICI)1096-8644(1998)107:27+\%3C65::AID-AJPA4\%3E3.0.CO;2-6.

Konigsberg, Lyle W, and Susan R Frankenberg. 1992. "Estimation of Age Structure in Anthropological Demography." American Journal of Physical Anthropology 89 (2): 235-56. 
Krajcarz, M. T., M. Krajcarz, B. Ginter, T. Goslar, and P. Wojtal. 2018. "Towards a Chronology of the Jerzmanowician - a New Series of Radiocarbon Dates from Nietoperzowa Cave (Poland)." Archaeometry 60 (2): 383-401. https://doi.org/https://doi.org/10.1111/arcm.12311.

Kramer, Karen L, Amanda Veile, and Erik Otárola-Castillo. 2016. "Sibling Competition \& Growth Tradeoffs. Biological Vs. Statistical Significance." PloS One 11 (3): e0150126.

Krol, Tessa N, Michael Dee, and Annet Nieuwhof. 2020. "The Chronology of Anglo-Saxon Style Pottery in Radiocarbon Dates: Improving the Typo-chronology." Oxford Journal of Archaeology 39 (4): 410-41.

Krus, Anthony M, and Lori Barkwill Love. 2020. "The Big Picture: Multiple Perspective Chronologies with Bayes and Beyond (Symposium)." In Society for American Archaeology 85th Annual Meeting.

Lindley, Dennis Victor. 1972. Bayesian Statistics: A Review. SIAM.

Litton, Clifford D, and Caitlin E Buck. 1996. "An Archaeological Example: Radiocarbon Dating." Markov Chain Monte Carlo in Practice, 466-86.

Loftus, Emma, Peter J Mitchell, and Christopher Bronk Ramsey. 2019. "An Archaeological Radiocarbon Database for Southern Africa." Antiquity 93 (370): 870-85.

Long, Tengwen, Mayke Wagner, and Pavel E. Tarasov. 2017. “A Bayesian Analysis of Radiocarbon Dates from Prehistoric Sites in the Haidai Region, East China, for Evaluation of the Archaeological Chronology." Journal of Archaeological Science: Reports 12: 81-90. https://doi.org/https://doi.org/10.1016/j.jasrep. 2017.01.024.

Lorentzen, Brita, Sturt W. Manning, and Deborah Cvikel. 2020. "Shipbuilding and Maritime Activity on the Eve of Mechanization: Dendrochronological Analysis of the Akko Tower Shipwreck, Israel." Journal of Archaeological Science: Reports 33: 102463. https://doi.org/https://doi.org/10.1016/j.jasrep.2020. 102463.

Lucy, Dave, RG Aykroyd, AM Pollard, and T Solheim. 1996. "A Bayesian Approach to Adult Human Age Estimation from Dental Observations by Johanson's Age Changes." Journal of Forensic Science 41 (2): 189-94.

Manning, Sturt W, Adam T Smith, Lori Khatchadourian, Ruben Badalyan, Ian Lindsay, Alan Greene, and Maureen Marshall. 2018. "A New Chronological Model for the Bronze and Iron Age South Caucasus: Radiocarbon Results from Project ArAGATS, Armenia." Antiquity 92 (366): 1530-51.

Marsh, Erik J., Andrew P. Roddick, Maria C. Bruno, Scott C. Smith, John W. Janusek, and Christine A. Hastorf. 2019. "Temporal Inflection Points in Decorated Pottery: A Bayesian Refinement of the Late Formative Chronology in the Southern Lake Titicaca Basin, Bolivia." Latin American Antiquity 30 (4): 798-817. https://doi.org/10.1017/laq.2019.73.

Marsh, Erik J, Ray Kidd, Dennis Ogburn, and Víctor Durán. 2017. "Dating the Expansion of the Inca 
Empire: Bayesian Models from Ecuador and Argentina." Radiocarbon 59 (1): 117.

Martisius, Naomi L., Shannon P. McPherron, Ellen Schulz-Kornas, Marie Soressi, and Teresa E. Steele. 2020. "A Method for the Taphonomic Assessment of Bone Tools Using 3d Surface Texture Analysis of Bone Microtopography." Archaeological and Anthropological Sciences 12 (10): 1-16.

Martisius, Naomi L., I Sidéra, MN Grote, Teresa E. Steele, Shannon P. McPherron, and Ellen Schulz-Kornas. 2018. "Time Wears on: Assessing How Bone Wears Using 3d Surface Texture Analysis." PlosS ONE 13 (11): e0206078. https://doi.org/https://doi.org/10.1371/journal.pone.0206078.

Marwick, Ben. 2017. "Computational Reproducibility in Archaeological Research: Basic Principles and a Case Study of Their Implementation." Journal of Archaeological Method and Theory 24 (2): 424-50.

Marwick, Ben, Chris Clarkson, Sue O'Connor, and Sophie Collins. 2016. "Early Modern Human Lithic Technology from Jerimalai, East Timor." Journal of Human Evolution 101: 45-64.

Maurer, A-F, Alain Person, Antoine Zazzo, Mathieu Sebilo, Vincent Balter, Florence Le Cornec, Valery Zeitoun, Elise Dufour, Annette Schmidt, and Marc de Rafelis. 2017. "Geochemical Identity of PreDogon and Dogon Populations at Bandiagara (Mali, 11th-20th Cent. AD)." Journal of Archaeological Science: Reports 14: 289-301.

McCall, Grant S. 2018. Strategies for Quantitative Research: Archaeology by Numbers. Routledge.

McElreath, Richard. 2020. Statistical Rethinking: A Bayesian Course with Examples in $R$ and Stan. CRC press.

Mendelsohn, Rebecca R. 2018. "The Chronology of the Formative to Classic Period Transition at Izapa: A Reevaluation." Latin American Antiquity 29 (2): 239-59.

Méhault, Ronan. 2017. "Applying a Bayesian Approach in the Northeastern North American Context: Reassessment of the Temporal Boundaries of the "Pseudo-Scallop Shell Interaction Sphere." Canadian Journal of Archaeology 41: 139-72.

Millard, Andrew. 2002. "Bayesian Approach to Sapwood Estimates and Felling Dates in Dendrochronology." Archaeometry 44 (1): 137-43.

Murray, John K., Jacob A. Harris, Simen Oestmo, Miles Martin, and Curtis W. Marean. 2020. "A New Approach to Identify Heat Treated Silcrete Near Pinnacle Point, South Africa Using 3d Microscopy and Bayesian Modeling." Journal of Archaeological Science: Reports 34: 102622.

Murtaugh, Paul A. 2014. "In Defense of P Values." Ecology 95 (3): 611-17. https://doi.org/https://doi. org/10.1890/13-0590.1.

Myers, OH. 1950. Some Applications of Statistics to Archaeology. Cairo: Serv. Antiq. Egypte.

Naylor, JC, and AFM Smith. 1988. "An Archaeological Inference Problem." Journal of the American Statistical Association 83 (403): 588-95. 
Neyman, Jerzy, and Egon Sharpe Pearson. 1933. "On the Problem of the Most Efficient Tests of Statistical Hypotheses." Philosophical Transactions of the Royal Society of London. Series A, Containing Papers of a Mathematical or Physical Character 231: 289-337.

Ortman, Scott G, Mark D Varien, and T Lee Gripp. 2007. "Empirical Bayesian Methods for Archaeological Survey Data: An Application from the Mesa Verde Region." American Antiquity, 241-72.

Osborn, Jo. 2019. "A Bayesian Approach to Andean Faunal Assemblages." Latin American Antiquity 30 (2): $354-72$.

Otárola-Castillo, Erik, and Melissa G. Torquato. 2018. "Bayesian Statistics in Archaeology." Annual Review of Anthropology 47 (1): 435-53. https://doi.org/10.1146/annurev-anthro-102317-045834.

Parkington, John, John W Fisher Jr, Simon Hoyte, Maria Lazarides, and Stephan Woodborne. 2020. "Contemporaneity and Entanglement: Archaeological Site Structure from a Bayesian Perspective." Journal of Archaeological Science: Reports 31: 102349.

Paulsson, B. Schulz. 2019. "Radiocarbon Dates and Bayesian Modeling Support Maritime Diffusion Model for Megaliths in Europe." Proceedings of the National Academy of Sciences 116 (9): 3460-65.

Perri, Angela R., Jeremy M. Koster, Erik Otárola-Castillo, Jessica L. Burns, and Catherine G. Cooper. 2019. "Dietary Variation Among Indigenous Nicaraguan Horticulturalists and Their Dogs: An Ethnoarchaeological Application of the Canine Surrogacy Approach." Journal of Anthropological Archaeology 55: 101066. https://doi.org/https://doi.org/10.1016/j.jaa.2019.05.002.

Pezo-Lanfranco, Luis, Sabine Eggers, Cecilia Petronilho, Alice Toso, Dione da Rocha Bandeira, Matthew Von Tersch, Adriana M. P. dos Santos, Beatriz Ramos da Costa, Roberta Meyer, and André Carlo Colonese. 2018. "Middle Holocene Plant Cultivation on the Atlantic Forest Coast of Brazil?" Royal Society Open Science 5 (9): 180432. https://doi.org/doi:10.1098/rsos.180432.

Plummer, Martyn. 2003. "JAGS: A Program for Analysis of Bayesian Graphical Models Using Gibbs Sampling." In Proceedings of the 3rd International Workshop on Distributed Statistical Computing, 124:1-10. Vienna, Austria.

Reimer, Paula J., William E. N. Austin, Edouard Bard, Alex Bayliss, Paul G. Blackwell, Christopher Bronk Ramsey, Martin Butzin, et al. 2020. "The IntCal20 Northern Hemisphere Radiocarbon Age Calibration Curve (0-55 Cal kBP).” Radiocarbon 62 (4): 725-57. https://doi.org/10.1017/RDC.2020.41.

Ricci, Paola, Maite Iris García-Collado, Josu Narbarte Hernández, Idoia Grau Sologestoa, Juan Antonio Quirós Castillo, and Carmine Lubritto. 2018. "Chronological Characterization of Medieval Villages in Northern Iberia: A Multi-Integrated Approach.” Eur. Phys. J. Plus 133 (9): 375. https://doi.org/10. 1140/epjp/i2018-12233-5.

Robert, Christian, and George Casella. 2011. "A Short History of Markov Chain Monte Carlo: Subjective 
Recollections from Incomplete Data." Statistical Science, 102-15.

Robertson, Ian G. 1999. "Spatial and Multivariate Analysis, Random Sampling Error, and Analytical Noise: Empirical Bayesian Methods at Teotihuacan, Mexico." American Antiquity, 137-52.

Rosenstock, Eva, Julia Ebert, Robert Martin, Andreas Hicketier, Paul Walter, and Marcus Groß. 2019. "Human Stature in the Near East and Europe Ca. 10,000-1000 BC: Its Spatiotemporal Development in a Bayesian Errors-in-Variables Model." Archaeological and Anthropological Sciences 11 (10): 5657-90. https://doi.org/10.1007/s12520-019-00850-3.

Sadr, Karim, C. Britt Bousman, Thomas A. Brown, Kamela G. Sekonya, Elias Sideras-Haddad, and Andrew B. Smith. 2017. "New Radiocarbon Dates and the Herder Occupation at Kasteelberg B, South Africa." Antiquity 91 (359): 1299-1313. https://doi.org/10.15184/aqy.2017.102.

Skelly, Robert, Bruno David, Matthew Leavesley, Fiona Petchey, Alu Guise, Roxanne Tsang, Jerome Mialanes, and Thomas Richards. 2018. "Changing Ceramic Traditions at Agila Ancestral Village, Hood Bay, Papua New Guinea." Australian Archaeology 84 (2): 181-95. https://doi.org/10.1080/03122417. 2018.1515146.

Smith, Mike, Alan N. Williams, and June Ross. 2017. "Puntutjarpa Rockshelter Revisited: A Chronological and Stratigraphic Reappraisal of a Key Archaeological Sequence for the Western Desert, Australia." Australian Archaeology 83 (1-2): 20-31. https://doi.org/10.1080/03122417.2017.1351673.

Snitker, Grant, Agustín Diez Castillo, C. Michael Barton, Joan Bernabeu Aubán, Oreto García Puchol, and Salvador Pardo-Gordó. 2018. "Patch-Based Survey Methods for Studying Prehistoric Human LandUse in Agriculturally Modified Landscapes: A Case Study from the Canal de Navarrés, Eastern Spain." Quaternary International 483: 5-22. https://doi.org/https://doi.org/10.1016/j.quaint.2018.01.034.

Spaulding, Albert C. 1953. "Statistical Techniques for the Discovery of Artifact Types." American Antiquity 18 (4): $305-13$.

Stewart, S. T., P. M. N. Hitchings, P. Bikoulis, and E. B. Banning. 2017. "Novel Survey Methods Shed Light on Prehistoric Exploration in Cyprus." Antiquity 91 (355): e3. https://doi.org/10.15184/aqy.2016.235.

Sturtz, Sibylle, Uwe Ligges, and Andrew E Gelman. 2005. "R2WinBUGS: A Package for Running WinBUGS from R."

Team, Stan Developent. 2019. "Stan Modeling Language Users Guide and Reference Manual." User's Guide Version 2.25. http://mc-stan.org/.

—. 2020. "RStan: The R Interface to Stan.” R Package Version 2.21.2. http://mc-stan.org/.

Tsukamoto, K, F Tokanai, T Moriya, and H Nasu. 2020. "Building a High-Resolution Chronology at the Maya Archaeological Site of El Palmar, Mexico." Archaeometry 62 (6).

Urwin, Quan Hua, Chris, and Henry Arifeae. 2018. "The Chronology of Popo, an Ancestral Village Site in 
Orokolo Bay, Gulf Province, Papua New Guinea." Australian Archaeology 84 (1): 90-97.

Veth, Ingrid Ward, Peter. 2017. "Early Human Occupation of a Maritime Desert, Barrow Island, North-West Australia." Quaternary Science Reviews 168: 19-29.

Vidgen, Bertie, and Taha Yasseri. 2016. "P-Values: Misunderstood and Misused." Frontiers in Physics 4: 6.

Wang, S., N. Chen, M. R. Capodiferro, T. Zhang, H. Lancioni, H. Zhang, Y. Miao, et al. 2017. "Whole Mitogenomes Reveal the History of Swamp Buffalo: Initially Shaped by Glacial Periods and Eventually Modelled by Domestication." Scientific Reports 7 (1): 4708. https://doi.org/10.1038/s41598-017-048302.

Wasserstein, Ronald L, Allen L Schirm, and Nicole A Lazar. 2019. "Moving to a World Beyond 'p< 0.05'." The American Statistician 73 (Sup1).

White, Gregory G, and Thomas F King. 2016. The Archaeological Survey Manual. Routledge.

Wolfhagen, Jesse. 2020. "Re-Examining the Use of the LSI Technique in Zooarchaeology." Journal of Archaeological Science 123: 105254. https://doi.org/https://doi.org/10.1016/j.jas.2020.105254.

Wolfhagen, Jesse, and Erik Otárola-Castillo. 2021. "Bayesian Archaeology (Symposium)." In Society for American Archaeology 86th Annual Meeting.

Wolfhagen, Jesse, and Max D. Price. 2017. "A Probabilistic Model for Distinguishing Between Sheep and Goat Postcranial Remains." Journal of Archaeological Science: Reports 12: 625-31.

Wright, David K., Junkyu Kim, Jiyoung Park, Jiwon Yang, and Jangsuk Kim. 2020. "Spatial Modeling of Archaeological Site Locations Based on Summed Probability Distributions and Hot-Spot Analyses: A Case Study from the Three Kingdoms Period, Korea." Journal of Archaeological Science 113: 105036. https://doi.org/https://doi.org/10.1016/j.jas.2019.105036.

Wright, David K., Scott MacEachern, and Jaeyong Lee. 2014. "Analysis of Feature Intervisibility and Cumulative Visibility Using GIS, Bayesian and Spatial Statistics: A Study from the Mandara Mountains, Northern Cameroon." PLOS ONE 9 (11): e112191. https://doi.org/10.1371/journal.pone.0112191.

Wynveldt, Federico, Bárbara Balesta, María Emilia Iucci, Celeste Valencia, and Gabriela Soledad Lorenzo. 2017. "Late Chronology in Hualfin Valley (Catamarca, Argentina): A Revisión from 14c Dating." Radiocarbon 59 .

Xiang, Hai, Jianqiang Gao, Dawei Cai, Yunbing Luo, Baoquan Yu, Langqing Liu, Ranran Liu, et al. 2017. "Origin and Dispersal of Early Domestic Pigs in Northern China." Scientific Reports 7 (1): 5602. https: //doi.org/10.1038/s41598-017-06056-8.

Yang, Yishi, Shanjia Zhang, Chris Oldknow, Menghan Qiu, Tingting Chen, Haiming Li, Yifu Cui, et al. 2019. "Refined Chronology of Prehistoric Cultures and Its Implication for Re-Evaluating Human-Environment 
Relations in the Hexi Corridor, Northwest China." Science China Earth Sciences 62 (10): 1578-90. https://doi.org/10.1007/s11430-018-9375-4. 